\title{
Mevalonate Availability Affects Human and Rat Resistance Vessel Function
}

\author{
Jean-Baptiste Roullet, ${ }^{*}$ Hong Xue, ${ }^{*}$ Chantal M. Roullet, ${ }^{\star}$ William S. Fletcher, ${ }^{\ddagger}$ Marilyn J. Cipolla, ${ }^{5}$ Christian T. Harker, ${ }^{5}$ \\ and David A. McCarron* \\ ${ }^{*}$ Department of Nephrology, Hypertension and Clinical Pharmacology; ${ }^{\ddagger}$ Department of Surgical Oncology; ${ }^{8}$ Departments of Surgery and \\ Physiology, Oregon Health Sciences University, Portland, Oregon 97201
}

\begin{abstract}
Previous data in rat conductance vessels indicated that cellular mevalonate contributes to vascular tone and systemic blood pressure control. Using exogenous mevalonate (M) or lovastatin, a 3-hydroxy-3-methyl-glutaryl CoA (HMGCoA) reductase inhibitor $(L)$, we characterized the role of mevalonate availability in resistance artery function, both in experimental animals and humans. Rat mesenteric artery resistance vessels (MARV, $n=9$ ) were incubated for $48 \mathrm{~h}$ with either $L, M, L+M$, or vehicle $(V)$ and tested for reactivity to $\mathrm{NE}$, serotonin, acetylcholine, atrial natriuretic peptide, and sodium nitroprusside (SNP). Lovastatin increased sensitivity to $\mathrm{NE}(P<0.03)$ and serotonin $(P$ $<0.003$ ), and significantly impaired the response to all three vasodilators. These effects were reversed by co-incubation with mevalonate. Mevalonate alone had no effect. In separate experiments, intravascular free $\mathrm{Ca}^{2+}$ concentration $\left({ }_{\mathrm{ivf}} \mathrm{Ca}^{2+}\right.$ ) was determined in fura-2AM loaded MARV. Basal iv $\mathrm{Ca}^{2+}$ was increased after a 48-h exposure to $L(52.7 \pm 4.6$ $\mathrm{nM}, \mathrm{L}$, vs. $29.7 \pm 2.4 \mathrm{nM}, \mathrm{V}, n=12, P<0.003$ ), as were ivf $\mathrm{Ca}^{2+}$ levels following stimulation with low (100 $\left.\mathrm{nM}\right)$ $\mathrm{NE}$ concentrations. Similar ivf $\mathrm{Ca}^{2+}$ concentrations were achieved during maximum contraction with NE (10 mM) in both groups. Human resistance arteries of human adipose tissue were also studied. Lovastatin increased the sensitivity to $\mathrm{NE}\left(\mathrm{ED}_{50}=372 \pm 56 \mathrm{nM}, \mathrm{V}\right.$, and $\left.99 \pm 33 \mathrm{nM}, \mathrm{L}, P<0.001\right)$ and significantly decreased the relaxation to acetylcholine and SNP of human vessels. We conclude that mevalonate availability directly contribute to resistance vessel function and vascular signal transduction systems in both experimental animals and humans. The study calls for the identification of non-sterol, mevalonate-derived vasoactive metabolites, and suggests that disorders of the mevalonate pathway can alter vascular tone and cause hypertension. (J. Clin. Invest. 1995. 96:239-244.) Key words: lovastatin - HMGCoA reductase inhibitors • vascular tone $\cdot$ cholesterol $\bullet$ isoprenoids.
\end{abstract}

Part of this work was presented at the American Society of Nephrology 26th annual meeting, Boston, MA, November 14-17, 1993.

Address correspondence to Jean-Baptiste Roullet, Department of Nephrology, Hypertension and Clinical Pharmacology, L-463, Oregon Health Sciences University, 3181 SW Sam Jackson Park Road, Portland, OR 97201. Phone: 503-494-8490; FAX: 503-494-5330.

Received for publication 15 November 1994 and accepted in revised form 20 March 1995.

J. Clin. Invest.

(C) The American Society for Clinical Investigation, Inc.

0021-9738/95/07/0239/06 \$2.00

Volume 96, July 1995, 239-244

\section{Introduction}

Cellular mevalonate production is tightly controlled by 3-hydroxy-3-methyl-glutaryl CoA (HMG-CoA) ${ }^{1}$ reductase (1). An early intermediate in the cholesterol pathway, mevalonate is also the precursor of non-sterol products which are critical for optimum cell function (2-6).

HMG-CoA reductase inhibitors, such as lovastatin, have been widely used as pharmacological tools to characterize mevalonate-dependent cell functions. These drugs are also used as cholesterol-lowering drugs. The role of mevalonate availability in vascular physiology has received very little attention: even though numerous studies have explored the impact of cholesterol on the vasculature, only a few have addressed the issue of an active participation of mevalonate and non-sterol derivatives in the maintenance of cardiovascular functions $(7,8)$. In a recent publication (9), we provided evidence that mevalonate availability was a novel regulatory mechanism contributing to the control of vascular tone and systemic blood pressure. In that study, in vitro exposure of rat conductance vessels (aorta) to lovastatin increased the response to vasoconstrictors and decreased endothelium-dependent and independent relaxations. These effects were independent of tissue changes in cholesterol content and reversed by co-incubation with mevalonate, suggesting that mevalonate derivatives other than cholesterol itself were vasoactive. Experiments conducted in vivo further supported this hypothesis, with lovastatin and mevalonate respectively increasing and decreasing systolic blood pressure in normotensive as well as hypertensive rats. Those observations were recently confirmed by Yamori et al. in a preliminary communication (10), using pravastatin, another HMG-CoA reductase inhibitor.

Resistance arteries, including mesenteric artery resistance vessel (MARV), are critical determinants of systemic blood pressure $(11,12)$. Therefore, the combined observation of impaired MARV reactivity and increased BP in animals receiving lovastatin (9) led us to postulate that lovastatin inhibition of the mevalonate pathway of resistance vessels increased vascular resistance and elevated systemic blood pressure. That hypothesis required experimental evidence of a direct effect of the drug on resistance vessels. Therefore, our first objectives in the present study was to describe the direct, in vitro effect of lovastatin and mevalonate on rat resistance vessels.

In our earlier study (9), lovastatin appeared to act on several pathways including NE-induced contraction and acetylcholine and sodium nitroprusside (SNP)-induced relaxation. It is known that stimulation of membrane receptors, such as the adrenergic and muscarinic receptors, triggers the elevation of

1. Abbreviations used in this paper: HMG-CoA, 3-hydroxy-3-methylglutaryl $\mathrm{CoA}$; ${ }_{\text {ivf }} \mathrm{Ca}^{2+}$, intravascular free calcium; L, lovastatin; LM, lovastatin +mevalonate; $M$, mevalonate; MARV, mesenteric artery resistance vessels; SNP, sodium nitroprusside. 
smooth muscle intracellular $\mathrm{Ca}^{2+}$. This, in turn, promotes contraction by catalyzing actin-myosin polymerization. Thus, we speculated that lovastatin modulates vascular reactivity by modifying intravascular levels of $\mathrm{Ca}^{2+}$. The experimental demonstration of this point was our second objective.

Since our earlier experiments (9) were conducted with rat vessels, the relevance of the concept of mevalonate availability to other species including humans was questionable. This issue is of importance not only because the ultimate goal of applied medical research is the extension of the findings to humans, but also because lovastatin and other HMG-CoA reductase inhibitors are currently prescribed to millions of individuals to lower plasma cholesterol. Therefore, our last objective was to characterize the effect of lovastatin on human resistance vessels.

\section{Methods}

Reagents. NE, acetylcholine, SNP, serotonin, rat synthetic atrial natriuretic peptide (ANP), DL-mevalonic acid lactone (mevalonolactone), transferrin and insulin were obtained from Sigma (St. Louis, MO). Fura-2AM was purchased from Molecular Probes (Eugene, OR). Lovastatin was a gift from Merck Sharp Dohme (Rahway, NJ).

Animal vessels. 12-14-wk-old male Wistar rats (Charles River Breeding Laboratories, Inc., Boston, MA) were used for all experiments. MARV (200-300 mm diameter) were isolated as previously described (13). Four vascular segments (1.5-2 mm length) from the second branch of the mesenteric artery were prepared from each animal $(n=9)$ and studied after a 48-h incubation with either lovastatin ( $\mathrm{L}, 5 \mu \mathrm{g} / \mathrm{ml})$, mevalonolactone (M, $10 \mathrm{mM})$, lovastatin + mevalonolactone (LM, 5 $\mu \mathrm{g} / \mathrm{ml}$ and $10 \mathrm{mM}$, respectively), or DMSO as vehicle $(\mathrm{V}, 0.1 \% \mathrm{vol} /$ vol). Preliminary experiments with shorter incubation time $(24 \mathrm{~h})$ were also conducted (three arterial segments per animal incubated with either lovastatin, mevalonate or DMSO, $n=9$ animals). All incubations were performed in DME/F-12 supplemented with antibiotics (penicillin and streptomycin $)$, transferrin $(5 \mathrm{mg} / \mathrm{liter})$ and insulin $(5 \mathrm{mg} / \mathrm{liter})$ at $37^{\circ} \mathrm{C}$ under a $5 \%-\mathrm{CO}_{2}$ atmosphere.

Human vessels. Four females and four males whose ages ranged from 44 to 74 and averaged $60.5 \mathrm{yr}$ were recruited in the Surgery department of our institution. They were admitted for lung cancer (one subject) or for peripheral vascular diseases with or without coronary artery disease ( 2 and 5 subjects, respectively). Four patients were hypertensive and three were diabetic. Plasma cholesterol levels ranged from 160 to $240 \mathrm{mg} / \mathrm{dl}$. None of them was receiving HMG-CoA reductase inhibitors at the time of the study. Small arteries were isolated from biopsies of subcutaneous fat after informed consent from the patients. The protocol was approved by the O.H.S.U. Institution Review Board. After careful dissection, two arterial segments per biopsy were incubated for $48 \mathrm{~h}$ in DME supplemented with antibiotics $\left(37^{\circ} \mathrm{C}, 5 \%-\mathrm{CO}_{2}\right.$ atmosphere), one with lovastatin $(5 \mathrm{mg} / \mathrm{ml})$, the other with DMSO.

Measurement of vascular reactivity. Rat or human arteries were mounted on a wire myograph capable of measuring isometric tension and tested for reactivity to vasoconstrictors and vasodilators in the absence of extracellular drug (14-16). The reactivity to NE and serotonin was first determined. Then, relaxation was examined after precontraction with NE. Endothelium-dependent relaxation was tested with acetylcholine; endothelium-independent relaxation with SNP, a direct activator of smooth muscle soluble guanylate cyclase, and with ANP $(0.1 \mu \mathrm{g} /$ $\mathrm{ml}$ ), an activator of the particulate guanylate cyclase. Responses are reported as absolute force normalized to axial length of the vessel (active tension in $\mathrm{mN} / \mathrm{mm}$ ) for contractions or as percent (\%) of pre-contraction with $\mathrm{NE}$ for relaxations ( $100 \%$ equals no relaxation). When appropriate, $\mathrm{ED}_{50}$ was calculated.

Determination of intravascular free calcium $\left({ }_{i v f} \mathrm{Ca}^{2+}\right.$ ) concentration. These experiments $(n=8-13)$ were conducted in MARV exposed to lovastatin $(5 \mu \mathrm{g} / \mathrm{ml})$ or vehicle for $48 \mathrm{~h}$. Before being mounted in the myograph, MARV were loaded with $50 \mu \mathrm{M}$ fura-2AM, a fluorescent $\mathrm{Ca}^{2+}$ indicator (17), in Hepes (10 mM)-buffered physiological saline,

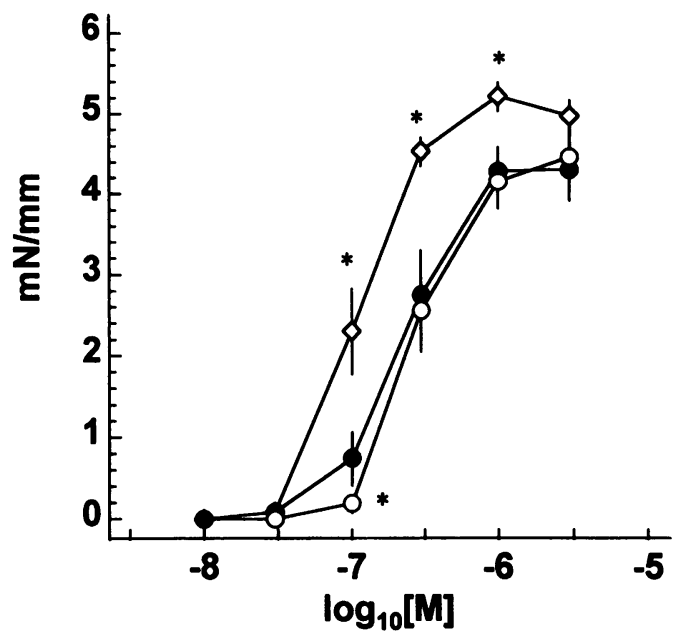

Figure 1. Response to NE of MARV $(n=9)$ incubated $(24 \mathrm{~h})$ with lovastatin $(\diamond)$, mevalonate $(O)$, or vehicle $(\bullet)$. * Significant difference $(P \leq 0.05)$ from vehicle-treated vessels.

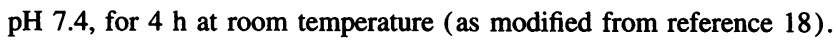
Then, basal and agonist (NE)-stimulated ${ }_{\mathrm{ivf}} \mathrm{Ca}^{2+}$ levels were measured with simultaneous active tension recording of the vessels maintained at $37^{\circ} \mathrm{C}$, using a dual wavelength spectrofluorometer (Spex Industries, Inc., Edison, $\mathrm{NJ}$ ), a Nikon microscope and a $25 \times$ water-oil immersion Zeiss lens. Maximum and minimum excitation ratios $(340 / 380 \mathrm{~nm})$ were determined as described $(17,19)$. In order to detect changes in sensitivity as well as in maximum response, two concentrations of NE, low $(100 \mathrm{nM})$ and high $(10 \mu \mathrm{M})$, were used.

Statistical analysis. Results were expressed as mean \pm SEM. Statistical significance was established using paired and unpaired Student's $t$ test.

\section{Results}

24-h incubation of rat MARV with lovastatin had little effect on vessel reactivity. There was an increased maximum response to $\mathrm{NE}(5.27 \pm 0.19 \mathrm{mN} / \mathrm{mm}$ and $4.41 \pm 0.34 \mathrm{mN} / \mathrm{mm}, P<0.04$ for $\mathrm{L}$ and $\mathrm{V}$, respectively), and a left-shift of the dose-response curve (Fig. 1). However, the decrease of NE-ED 50 did not reach statistical significance: $116.3 \pm 19.2 \mathrm{nM}$ (L) vs. $245.6 \pm 63.0 \mathrm{nM}$ (V), $P=0.09$. Mevalonate had no effect on the response of the vessels to NE (Fig. 1). The responses to serotonin, acetylcholine, SNP and ANP were identical in control, lovastatin and mevalonate-treated arteries (data not shown).

48-h incubation with lovastatin significantly increased the sensitivity of MARV to NE. $\mathrm{ED}_{50}(\mathrm{nM})$ were $182 \pm 60$ and $33 \pm 8$ for $\mathrm{V}$ and $\mathrm{L}$, respectively $(P<0.03)$. No change in the maximum response to the hormone was observed (Fig. 2). As shown on the same figure, addition of mevalonate to the medium, together with lovastatin, normalized the response to NE $\left(\mathrm{ED}_{50}=232 \pm 47 \mathrm{nM}, P<0.004\right.$ vs. $\mathrm{L}, P=\mathrm{NS}$ vs. V), while mevalonate alone decreased the sensitivity to $\mathrm{NE}\left(\mathrm{ED}_{50}\right.$ $=232 \pm 47 \mathrm{nM}, P=0.06$ vs. V). Similarly, the sensitivity to serotonin was increased by lovastatin and normalized by mevalonate addition (Fig. 3). $\mathrm{ED}_{50}(\mathrm{nM})$ were $138 \pm 21(\mathrm{~V})$, $61 \pm 7$ (L, $P<0.003$ ) and $184 \pm 34$ (LM, $P<0.005$ vs. L, $P$ $=$ NS vs. V). Mevalonate alone had no effect on the response to serotonin $\left(\mathrm{ED}_{50}=186 \pm 25 \mathrm{nM}, P=\mathrm{NS}\right.$ vs. V). A significant impairment of the acetylcholine-induced relaxation was observed in vessels incubated $(48 \mathrm{~h})$ with lovastatin as indicated by a right-shift of the dose-response curve and a decreased 


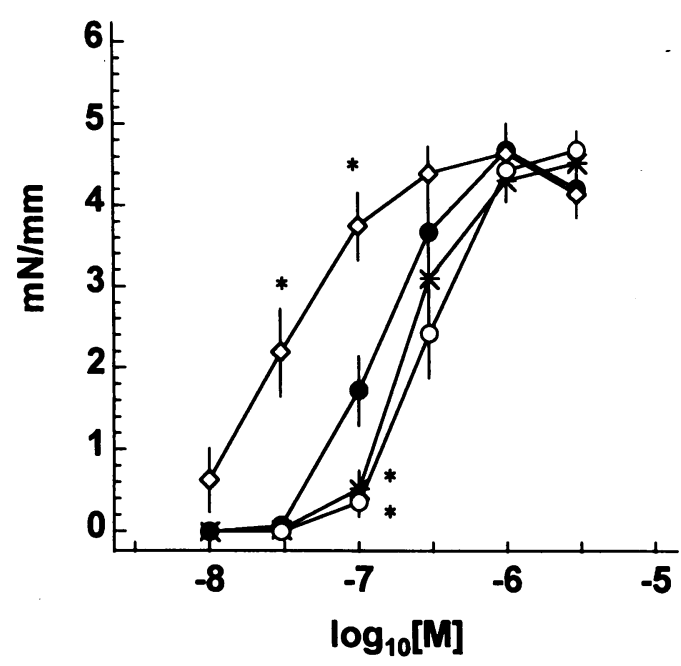

Figure 2. Response to NE of MARV $(n=9)$ incubated $(48 \mathrm{~h})$ with lovastatin $(\diamond)$, mevalonate $(O)$, lovastatin + mevalonate $(*)$, or vehicle $(\bullet)$. ${ }^{*}$ Significant difference $(P \leq 0.05)$ from vehicle-treated vessels.

maximum response (Fig. 4). Addition of mevalonate significantly reversed the effect of lovastatin (same figure). Mevalonate alone had no effect. Because the ANP-dependent relaxation of the resistance vessels is slow to develop, the rate of relaxation rather than the dose-response to ANP was determined for each preparation (Fig. 5). Lovastatin significantly reduced the rate of relaxation of the arteries by comparison with control vessels. The effect of the drug was significantly attenuated by addition of mevalonate. Mevalonate alone accelerated the ANP-induced relaxation, though not significantly. SNP-induced relaxations are presented in Fig. 6. Lovastatin significantly impaired the response to SNP as indicated by a shift of the dose-response curve to the right of the control curve, an effect almost totally abolished by co-incubation with mevalonate. Mevalonate alone had no effect on SNP-induced relaxation.

Basal ${ }_{\text {ivf }} \mathrm{Ca}^{2+}$ concentration was significantly increased in

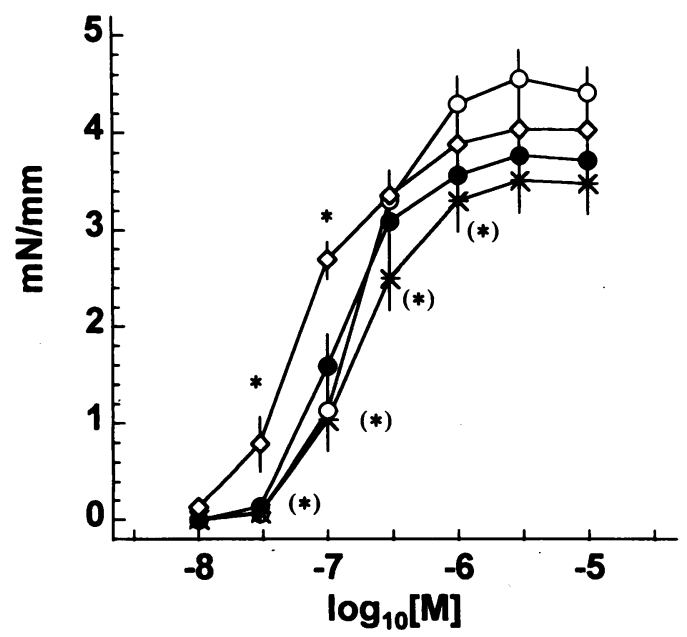

Figure 3. Response to serotonin of MARV $(n=9)$ incubated $(48 \mathrm{~h})$ with lovastatin $(\diamond)$, mevalonate $(0)$, lovastatin + mevalonate $(*)$, or vehicle $(\bullet)$. * Significant difference $(P \leq 0.05)$ from vehicle-treated vessels and ${ }^{(*)}$ significant difference $(P \leq 0.05)$ from lovastatin-treated vessels.

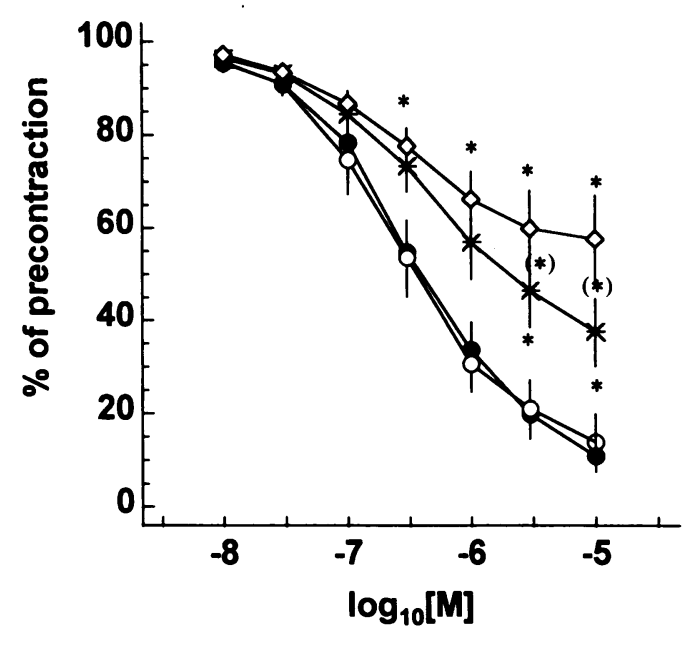

Figure 4. Response to acetylcholine of MARV $(n=9)$ incubated (48 h) with lovastatin $(\diamond)$, mevalonate $(0)$, lovastatin + mevalonate $(*)$, or vehicle $(\bullet)$. * Significant difference $(P \leq 0.05)$ from vehicle-treated vessels and ${ }^{(*)}$ significant difference $(P \leq 0.05)$ from lovastatin-treated vessels.

vessels treated with lovastatin by comparison with controls: $52.7 \pm 4.6 \mathrm{nM}$ vs. $29.7 \pm 2.4 \mathrm{nM}(n=12, P<0.003)$ for $\mathrm{L}$ and $\mathrm{V}$, respectively. Stimulation of the vessels with NE increased ${ }_{i v f} \mathrm{Ca}^{2+}$ concentrations in a dose-dependent relationship (Fig. 7). ivf $\mathrm{Ca}^{2+}$ levels following stimulation with low NE concentrations $(100 \mathrm{nM})$ were significantly higher in lovastatin-treated arteries than in control vessels. In contrast, similar ${ }_{\text {ivf }} \mathrm{Ca}^{2+}$ concentrations were achieved during maximum contraction (10 $\mu \mathrm{M} \mathrm{NE}$ ).

Exposure of human resistance arteries $(270 \pm 19 \mathrm{~mm}$ diameter) to lovastatin induced vascular reactivity changes similar to those observed in the rat vessels. The sensitivity but not the maximum response to $\mathrm{NE}$ was increased (Fig. 8). $\mathrm{ED}_{50}(\mathrm{nM})$ were $372 \pm 56$ and $99 \pm 33$ for $\mathrm{V}$ and $\mathrm{L}$, respectively, $P$ $<0.001$ ). Both the acetylcholine and the SNP-induced relaxations of the human resistance vessels were significantly re-

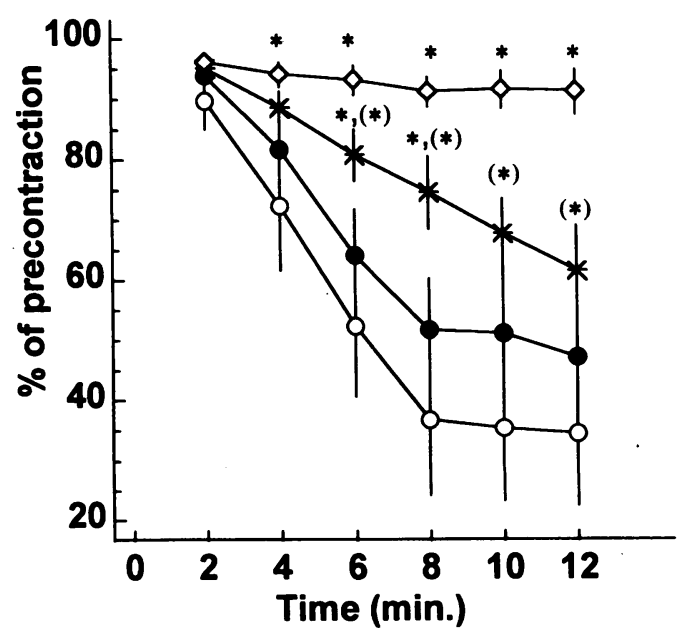

Figure 5. Response to ANP of MARV $(n=9)$ incubated $(48 \mathrm{~h})$ with lovastatin $(\diamond)$, mevalonate $(0)$, lovastatin + mevalonate $(*)$, or vehicle $(\bullet)$. * Significant difference $(P \leq 0.05)$ from vehicle-treated vessels and ${ }^{(*)}$ significant difference $(P \leq 0.05)$ from lovastatin-treated vessels. 


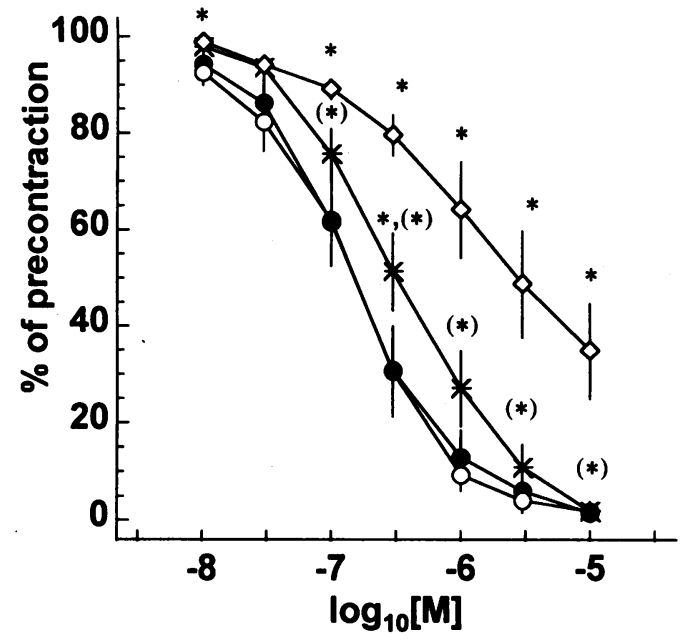

Figure 6. Response to SNP of MARV $(n=9)$ incubated $(48 \mathrm{~h})$ with lovastatin $(\diamond)$, mevalonate $(0)$, lovastatin + mevalonate $(*)$, or vehicle $(\bullet)$. * Significant difference $(P \leq 0.05)$ from vehicle-treated vessels and ${ }^{(*)}$ significant difference $(P \leq 0.05)$ with lovastatin-treated vessels.

duced as compared to controls (Fig. 9 and 10). There was no relationship between the effects of lovastatin and patient characteristics (data not shown).

\section{Discussion}

The study demonstrates that mevalonate availability has a direct impact on the functional properties of resistance arteries: mevalonate deficiency increases intracellular $\mathrm{Ca}^{2+}$, enhances the response to vasoconstrictors and impairs the response to vasodilators, whereas addition of mevalonate to the vessels restores pressor and depressor responsiveness. The study confirms in resistance vessels our previous findings in conductance vessels and provides evidence that mevalonate availability also regulates the contractility of resistance arteries in humans.

Lovastatin was used as a means to limit mevalonate production and cellular availability. The specificity of action of the drug was established by the ability of exogenous mevalonate to restore normal vascular functions. The concentrations of lo-

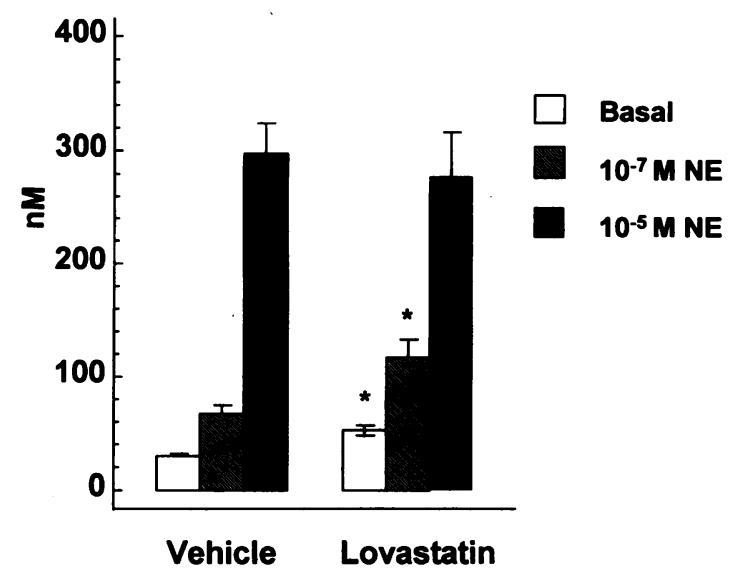

Figure 7. Basal and NE-stimulated ${ }_{\text {ivf }} \mathrm{Ca}^{2+}$ of MARV incubated (48 h) from lovastatin or vehicle. * Significant difference $(P \leq 0.05)$ from vehicle-treated vessels.

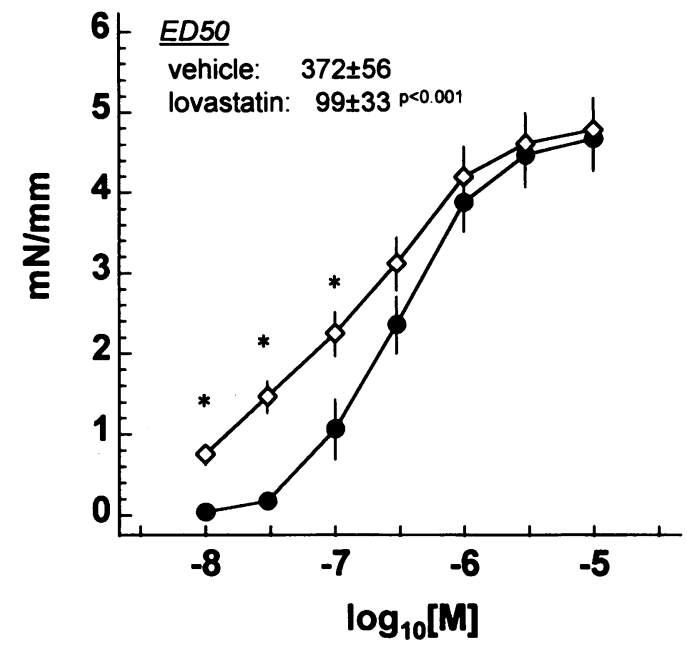

Figure 8. Response to NE of human resistance arteries $(n=8)$ incubated $(48 \mathrm{~h})$ with lovastatin $(\diamond)$ or vehicle $(\bullet)$. $*$ Significant difference $(P$ $\leq 0.05$ ) from vehicle-treated vessels.

vastatin $(5 \mu \mathrm{g} / \mathrm{ml})$ and mevalonate ( $10 \mathrm{mM})$ have been widely used for pharmacological exploration of the mevalonate pathway $(2,20-23)$, although they are not necessarily therapeutic. At these concentrations, lovastatin certainly reduces cellular mevalonate availability, but does not likely affect vascular cholesterol content. Such a situation has been observed in several other reports including ours with rat aortic rings $(9,24,25)$. It is not surprising because vascular cholesterol synthesis unlike hepatic or actively replicating cell synthesis is very low (26, 27 ). In addition, it is known that excess cholesterol in vascular smooth muscle increases reactivity to vasoconstrictors (28): therefore, if lovastatin had decreased vascular cholesterol concentration in our experiments, one would have expected to observe a decrease in reactivity to NE and not an increase (see Figs. 1, 2, and 8). Altogether, these observations suggest that lovastatin regulates the metabolic availability of non-sterol product(s) of the mevalonate pathway rather than cholesterol itself. The identity of these metabolites remains to be deter-

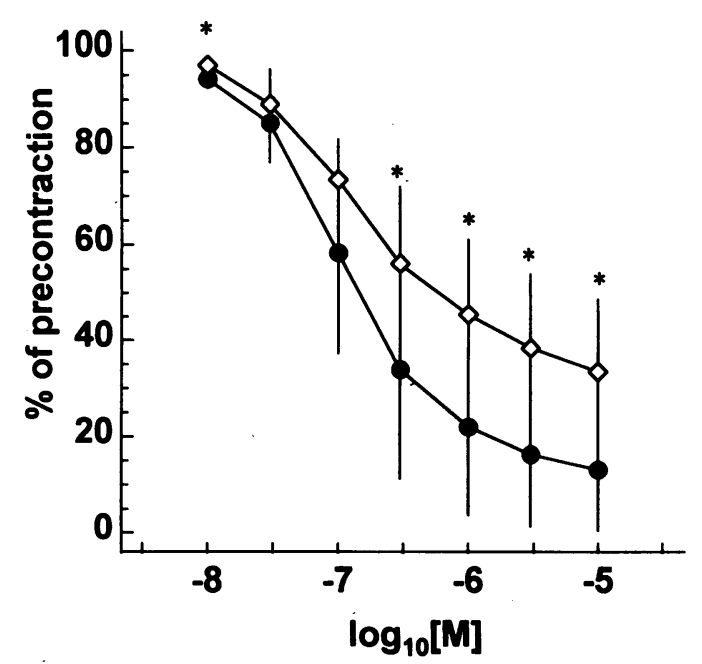

Figure 9. Response to acetylcholine of human resistance arteries ( $n$ $=8$ ) incubated $(48 \mathrm{~h})$ with lovastatin $(\diamond)$, or vehicle $(\bullet)$. * Significant difference $(P \leq 0.05)$ from vehicle-treated vessels. 


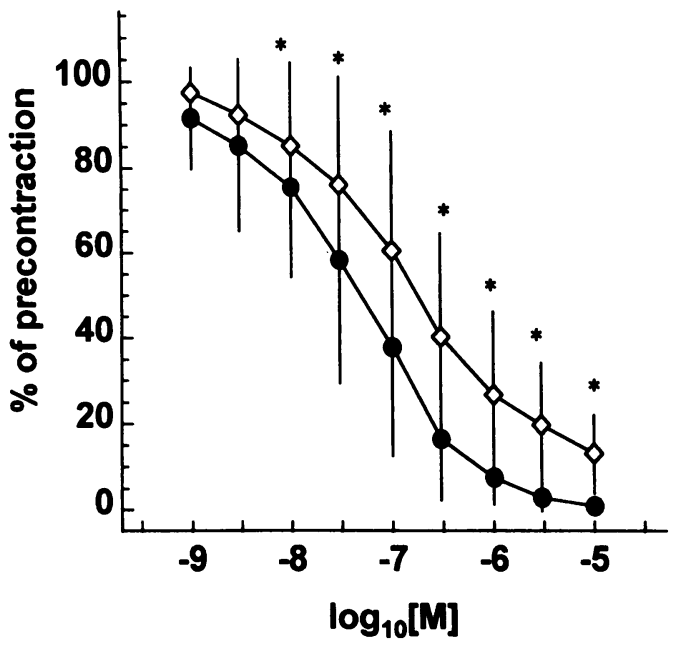

Figure 10. Response to SNP of human resistance arteries $(n=8)$ incubated $(48 \mathrm{~h})$ with lovastatin $(\diamond)$ or vehicle $(\bullet)$. * Significant difference $(P \leq 0.05)$ with vehicle-treated vessels.

mined. However, the recently discovered role of mevalonatederived isoprenoids in modulating the activity of GTP-binding proteins (3-6) offers a promising perspective, as vascular reactivity is in large part dependent on GTP-binding protein-mediated signal transduction.

Lovastatin increased sensitivity to NE and serotonin. Lovastatin effect on NE is similar to what we observed with aortic rings incubated with the drug and with resistance arteries of animals treated with it (9). The effect on serotonin-induced contraction has not been reported before and suggests that signal transduction steps common to both NE and serotonin are affected. As discussed below, greater availability of ${ }_{\text {ivf }} \mathrm{Ca}^{2+}$ should increase sensitivity to NE and serotonin. However, modifications of the affinity of the receptors for their ligands or alteration of signal transduction pathways of the vascular smooth muscle other than intracellular $\mathrm{Ca}^{2+}$ could also play a role.

Endothelium-dependent and independent relaxations were reduced by lovastatin in both human and rat resistance arteries. A similar impact of lovastatin was observed previously by us in vivo and in vitro (9). Our experiments cannot clearly separate the effect of lovastatin on the endothelium from that on the smooth muscle since the response to SNP was also impaired. When considering the relaxation curves of vessels treated with both lovastatin and mevalonate, full relaxation can be achieved with maximum concentrations of SNP (Fig. 5) but not with acetylcholine (Fig. 4), suggesting that lovastatin may affect the endothelial cells and the smooth muscle cells of the resistance vessels differentially.

The impact of lovastatin on contraction and relaxation could be partly mediated by the high basal ${ }_{\mathrm{ivf}} \mathrm{Ca}^{2+}$ levels as ${ }_{\mathrm{ivf}} \mathrm{Ca}^{2+}$ is a determinant of smooth muscle contraction. As lovastatin increases basal ${ }_{\text {ivf }} \mathrm{Ca}^{2+}$, less NE and more acetylcholine or SNP is needed to initiate contraction and relaxation respectively. This hypothesis does not take in account the potential stimulating effect of high ${ }_{\text {ivf }} \mathrm{Ca}^{2+}$ on endothelial nitric oxide production, a mechanism by which Ach-dependent relaxation should be enhanced rather than impaired. Thus, additional factors may be involved in lovastatin action. A recent study by Hrboticky et al. (24) showed that lovastatin stimulated the synthesis of $\mathrm{TXB}_{2}$, the stable degradation product of vasoconstrictor $\mathrm{TXA}_{2}$, in human monocytic Mono Mac6 cells. If stimulation of throm- boxane synthesis occurs in vessels exposed to lovastatin, the liberated $\mathrm{TXA}_{2}$ would likely $(a)$ activate the phospholipase Cinositol phosphate system of the smooth muscle and trigger the elevation of basal ${ }_{\mathrm{ivf}} \mathrm{Ca}^{2+}$, and $(b)$ imbalance the release of vasoconstrictors and vasodilators during Ach stimulation with a net reduction in Ach responsiveness. A similar hypothesis has been proposed to explain impairment of endothelium-dependent relaxation in experimental models of hypertension $(29,30)$ and in atherosclerotic vessels $(31,32)$. Direct measurement of $\mathrm{NO}$ or prostaglandin production in lovastatin-treated vessels would clarify those issues.

The effect of lovastatin on ${ }_{\text {ivf }} \mathrm{Ca}^{2+}$ in the resistance vessels is in apparent contrast with previous reports which addressed the issue of HMG-CoA reductase inhibition and cellular $\mathrm{Ca}^{2+}$ homeostasis $(25,33)$. The discrepancy between our findings and those of others could be attributed to the tissue difference (embryonic cells in culture vs. intact vessels) or could reflect drug differences (simvastatin in reference 25 , vs. lovastatin). Nonetheless, we believe that our observation of increased ${ }_{i v f} \mathrm{Ca}^{2+}$ in lovastatin vessels is more relevant to the in vivo situation as it is associated with parallel functional changes in intact vessels.

Incubation with mevalonate normalized the response to vasoconstrictors and to vasodilators in lovastatin-treated vessels, as previously observed in aortic rings (9). Mevalonate alone had no significant impact on vascular reactivity except for a marginal effect on NE-induced contraction (Fig. 6) observed after $48 \mathrm{~h}$ of incubation. This is in contrast with what we observed in vitro for large vessels (9), in which mevalonate alone decreased NE-induced contraction and enhanced acetylcholine and SNP-dependent relaxations, but in agreement with our in vivo results showing no effect of oral mevalonate on resistance vessels. Structural or functional differences may account for the discrepancy between conductance and resistance vessel responses to mevalonate.

Our study is the first report of an effect of mevalonate availability on human resistance vessels. Together with previous reports, including ours, of impaired mevalonate metabolism in spontaneously hypertensive rats (34-36), our data strongly suggests that genetic or acquired disorders of the mevalonate pathway may cause vascular dysfunction and possibly hypertension in humans. This possibility needs to be explored in future appropriate experiments.

The effect of lovastatin on human arteries also raises the possibility that therapeutic use of HMG-CoA reductase inhibitors has an effect on the vasculature in humans. This possibility has received little attention so far, despite the fact that more than three million patients are currently receiving this therapy in the United States. Investigators have recently provided preliminary evidence of the cardiovascular effects of HMG-CoA reductase inhibitors (37-39). However, no study has yet explored the effect of these drugs on resistance arteries ex vivo. Large clinical trials testing the safety of these drugs did not report any adverse impact of HMG-CoA reductase inhibitors on systemic blood pressure (40-41). It is essential to note, however, that none of these trials were designed to evaluate properly that outcome: as much as $40 \%$ (40) and 55\% (41) of the study subjects were hypertensive and/or on antihypertensive medication. Nonetheless, it is possible that the drug levels produced during lovastatin therapy are not high enough to induce a significant change in vascular tone. It is also possible that the reduction in low-density lipoprotein (LDL) and oxidized LDL levels following lovastatin therapy are offsetting the action of 
the drug on intracellular $\mathrm{Ca}^{2+}$ since LDLs can raise intracellular $\mathrm{Ca}^{2+}(42,43)$.

In conclusion, we have demonstrated that mevalonate availability regulates $\mathrm{Ca}^{2+}$ homeostasis in small arteries and modulates vascular tone. The existence in the arterial wall of non-sterol mevalonate derivatives with vasoactive properties is postulated as well as the possibility that metabolic disorders of the mevalonate pathway contribute to the pathogenesis of cardiovascular diseases, including essential hypertension. Finally, the study suggests that clinical investigations are necessary in order to fully characterize the vascular consequences of mevalonate deficiency during therapeutic inhibition of HMG-CoA reductase.

\section{Acknowledgments}

This study was supported in part by National Institiue of Diabetes and Digestive and Kidney Diseases, Clinical Nutrition Research Unit, Research Grant P30DK-40566-04.

\section{References}

1. Brown, M. S., and J. L. Goldstein. 1980. Multivalent feedback regulation of HMG CoA reductase, a control mechanism coordinating isoprenoid synthesis and cell growth. J. Lipid Res. 21:505-517.

2. Goldstein, J. L., and M. S. Brown. 1991. Regulation of the mevalonate pathway. Nature (Lond.). 343:425-430.

3. Sinensky, M., and R. J. Lutz. 1992. The prenylation of proteins. Bivessays. 14:25-31.

4. Glomset, J. A., M. H. Gelb, and C. C. Farnsworth. 1990. Prenyl proteins in eukaryotic cells: a new type of membrane anchor. TIBS (Trends Biochem. Sci.). 15:109-112

5. Ohguro, H., Y. Fukada, T. Takao, Y. Shimonishi, T. Yoshizawa, and T. Akino. 1991. Carboxyl methylation and farnesylation of transducin $\gamma$-subunit synergistically enhance its coupling with metarhodopsin-II. EMBO(Eur. Mol. Biol. Organ.) J. 10:3669-3674.

6. Iniguez-Lluhi, J. A., M. I. Simon, J. D. Robishaw, and A. G. Gilman. 1992. G-Protein $\beta \gamma$ subunits synthesized in Sf9 cells. Functional characterization and the significance of prenylation of $\gamma$. J. Biol. Chem. 267:23409-23417.

7. Okamoto, H., H. Kawaguchi, H. Togashi, M. Minami, H. Saito, and H. Yasuda. 1991. Effect of coenzyme-Q10 on structural alterations in the renal membrane of stroke-prone spontaneously hypertensive rats. Biochem. Med. Metab. Biol. 45:216-226.

8. Kawahara, Y., M. Kawata, M. Sunako, S. Araki, M. Koide, T. Tsuda, H. Fukuzaki, and Y. Takai. 1991. Small GTP-binding proteins in bovine aortic smooth muscle. Jpn. Circ. J. 55:1036-1043.

9. Roullet, J. -B., H. Xue, A. S. Pappu, C. M. Roullet, S. Holcomb, and D. A. McCarron. 1993. Mevalonate availability and cardiovascular functions. Proc. Natl. Acad. Sci. USA. 90:11728-11732.

10. Yamori, Y., N. Li, K. Kizawa, M. Sawamura, Y. Nara, and K. Ikeda. 1994. HMG-CoA reductase CoA reductase inhibitor increases blood pressure in SHR and WKY/Izm. Clin. Exp. Pharmacol. Physiol. S1:33. (Abstr.)

11. Boudier, H. A. J. S., J. L. M. L. Lenoble, M. W. J. Messing, M. S. P. Huijberts, F. A. C. Lenoble, and H. Vanessen. 1992. The microcirculation and hypertension. J. Hypertens. 10:S147-S156.

12. Mulvany, M. J., and C. Aalkjaer. 1990. Structure and function of small arteries. Physiol. Rev. 70:921-961.

13. Bukoski, R. D., and H. Xue. 1993. On the vascular inotropic action of 1,25- $(\mathrm{OH})_{2}$ vitamin $\mathrm{D}_{3}$. Am. J. Hypertens. 6:388-389.

14. Mulvany, M. J., and W. Halpern. 1977. Contractile properties of small arterial resistance vessels in spontaneously hypertensive and normotensive rats. Circ. Res. 41:19-26.

15. Roullet, J. -B., H. Xue, D. A. McCarron, S. Holcomb, and W. M. Bennett. 1994. Vascular mechanisms of cyclosporin-induced hypertension in the rat. $J$. Clin. Invest. 93:2244-2250.

16. Poston, L., R. G. Woolfson, and J. E. Graves. 1993. Effects of sodiumtransport inhibition in human resistance arteries. J. Cardiovasc. Pharmacol. 22:S1-S3.

17. Grynkiewicz, G., M. Poenie, and R. Y. Tsien. 1983. A new generation of $\mathrm{Ca}^{2+}$ indicators with greatly improved fluorescence properties. J. Biol. Chem. 260:3440-3450.

18. Himpens, B., G. Matthijs, A. V. Somlyo, T. M. Butler, and A. P. Smlyo. 1988. Cytoplasmic free calcium, myosin light chain phosphorylation, and force in phasic and tonic smooth muscle. J. Gen. Physiol. 92:713-729.

19. Bukoski, R. D. 1990. Intracellular $\mathrm{Ca}^{2+}$ metabolism of isolated resistance arteries and cultured vascular myocytes of spontaneously hypertensive and WistarKyoto normotensive rats. J. Hypertens. 8:37-43.

20. Falke, P., I. Mattiasson, L. Stavenow, and B. Hood. 1989. Effects of a competitive inhibitor (mevinolin) of 3-hydroxy-3-methylglutaryl coenzyme A reductase on human and bovine endothelial cells, fibroblasts and smooth muscle cells in vitro. Pharmacol. Toxicol. 64:173-176.

21. Williams, M. L., G. K. Menon, and K. P. Hanley. 1992. HMG-CoA reductase inhibitors perturb fatty acid metabolism and induce peroxisomes in keratinocytes. J. Lipid Res. 33:193-208.

22. O'Donnell, M., B. L. Kasiske, Y. Kim, D. Atluru, and W. F. Keane. 1993. Lovastatin inhibits proliferation of rat mesangial cells. J. Clin. Invest. 91:83-87.

23. Sviridov, D. D., I. G. Safonova, M. Y Pavlov, V. A. Kosykh, E. A. Podrez, A. S. Antonov, I. V. Fuki, and V. S. Repin. 1990. Inhibition of cholesterol synthesis by lovastatin tested on six human cell types in vitro. Lipids. 25:177-179.

24. Hrboticky, N., L. Tang, B. Zimmer, I. Lux, and P. C. Weber. 1994. Lovastatin increases arachidonic acid levels and stimulates thromboxane synthesis in human liver and monocytic cell lines. J. Clin. Invest. 93:195-203.

25. Ng, L. L., J. E. Davies, and R. J. H. Wojcikiewicz. 1994. 3-Hydroxy-3methyl glutaryl coenzyme A reductase inhibition modulates vasopressin-stimulated $\mathrm{Ca}^{2+}$ response in rat $\mathrm{A} 10$ vascular smooth muscle cells. Circ. Res. 74:173181 .

26. Endo, A., Y. Tsujita, M. Kuroda, and K. Tanzawa. 1979. Effects of ML236B on cholesterol metabolism in mice and rats: lack of hypocholesterolemic activity in normal animals. Biochim. Biophys. Acta 575:266-276.

27. Walsh, M. R., S. W. Teal, and W. Gamble. 1969. Biosynthesis of cholesterol by bovine aorta and the mechanism of action of $\alpha$ ara-chlorophenoxyisobutyric acid. Arch. Biochem. Biophys. 130:7-18.

28. Broderick, R., R. Bialecki, and T. N. Tulenko. 1989. Cholesterol-induced changes in rabbit arterial smooth muscle sensitivity to adrenergic stimulation. Am. J. Physiol. 257:H170-H178.

29. Fu-Xiang, D., J. Skopec, A. Diederich, and D. Diederich. 1992. Prostaglandin $\mathrm{H}_{2}$ and thromboxane $A_{2}$ are contractile factors in intrarenal arteries of spontaneously hypertensive rats. Hypertension. 19:795-798.

30. Kato, T., Y. Iwama, K. Okumura, H. Hashimoto, T. Ito, and T. Satake. 1990. Prostaglandin H2 may be the endothelium-derived contracting factor released by acetylcholine in the aorta of the rat. Hypertension. 15:475-481.

31. Wang, T., P. Falardeu, and W. S. Powell. 1991. Synthesis of prostaglandins and thromboxane $\mathrm{B}_{2}$ by cholesterol-fed rabbits. Arterioscler. Thromb. 11:501508.

32. Henriksson, P., M. Stamberger, and U. Dicsfalusy. 1987. Increased aortic thromboxane production in experimental atherosclerosis. Prostaglandines Leukot. Med. 29:71-77.

33. Renaud, J. F., A. Schmid, G. Romey, J. L. Nano, and M. Lazdunski. 1986 Mevinolin, an inhibitor of cholesterol biosynthesis drastically depresses $\mathrm{Ca}^{2+}$ channel activity and uncouples excitation from contraction in cardiac cells in culture. Proc. Natl. Acad. Sci. USA. 83:8007-8011.

34. Sawamura, M., Y. Nara, and Y. Yamori. 1992. Liver mevalonate 5pyrophosphate decarboxylase is responsible for reduced serum cholesterol in stroke-prone spontaneously hypertensive rat. J. Biol. Chem. 267:6051-6055.

35. Sawamura, M., N. Li, Y. Nara, and Y. Yamori. 1993. Proliferative effect of mevalonate metabolites other than isoprenoids on cultured vascular smooth muscle cells. Clin. Exp. Pharmacol. Physiol. 20:509-514.

36. Roullet, J.-B., M. Nakamura, C. M. Roullet, A. M. Dolney, and D. A. McCarron. 1994. Prenylated proteins in rat aorta and vascular smooth muscle cells: abnormal prenylation in spontaneously hypertensive rats (SHR). Am. J. Hypertens. 7:93A.(Abstr.)

37. Straznicky, N. E., W. J. Louis, W. Lam, and L. G. Howes. 1994. Effects of pravastatin and placebo on cardiovascular reactivity in hypercholesterolaemic patients with mild hypertension. J. Hypertens. 12:S129.(Abstr.)

38. Bedarida, G. V., E. Bushell, W. E. Haefeli, T. F. Blaschke, and B. B Hoffman. 1993. Responsiveness to bradykinin in veins of hypercholesterolemic humans. Circulation. 88:2754-2761.

39. Kool, M. J. F., F. A. T. Lustermans, H. A. Kragten, H. A. J. Struijker Boudier, I. Hoogendam, and L. M. A. B. Van Bortel. 1994. Lowering cholesterol in patients with mild hypercholesterolemia does not improve large artery compliance. J. Hypertens. 12:11. (Abstr.)

40. Bradford, R. H., C. L. Shear, A. N. Chremos, C. Dujovne, M. Downton, F. A. Franklin, A. L. Gould, M. Hesney, J. Higgins, D. Hurley, A. Langendorfer, D. T. Nash, J. L. Pool, and H. Schnaper. 1991. Expanded clinical evaluation of lovastatin (EXCEL) study results. Arch. Intern. Med. 151:43-49.

41. Scandinavian Simvastatin Survival Study Group. 1994. Randomized trial of cholesterol lowering in 4444 patients with coronary heart disease: the Scandinavian Simvastatin Survival Study (4S). Lancet. 344:1383-1389.

42. Block, L. H., M. Knorr, E. Vogt, R. Locher, N. Vetter, P. Groscurth, B. Y. Qiao, D. Pommetta, R. James, M. Regenas, and A. Pletscher. 1988. Low density lipoprotein causes general cellular activation with increased phosphatidylinositol turnover and lipoprotein catabolism. Proc. Natl. Acad. Sci. USA. 85:885-889.

43. Weisser, B., R. Locher, T. Mengden, and W. Vetter. 1992. Oxidation of low density lipoprotein enhances its potential to increase intracellular free calcium concentration in vascular smooth muscle cells. Arterioscler. Thromb. 12:231236. 